\title{
THE RELATIONSHIP BETWEEN QUALITY OF WORK LIFE AND OCCUPATIONAL STRESS AMONG HEAD NURSES IN PORT SAID HOSPITALS
}

\author{
Ghada Ahmed $^{1}$, Sanaa AbdElazeem ${ }^{2}$, Hind Abdallah, ${ }^{3}$ \\ 1 (Nursing administration, technical institute of nursing, Port Said, Egypt) \\ 2(Nursing administration, Faculty of Nursing, Port Said University, Egypt) \\ 3(Nursing administration, Faculty of Nursing, Port Said University, Egypt)
}

\begin{abstract}
Background: The interest in work and health organization in relation to quality of work life (QWL) has increased due to many positive outcomes as job satisfaction, increased productivity and less occupational stress. Aim: The study aimed to investigate the relationship between quality of work life and occupational stress among head nurses at Port Said Hospitals. Methods: A descriptive correlation research design was utilized with total sample of (85) head nurse. Tools of data collection: The data were collected by using two tools; Quality of nursing work life scale (QNWL) and Occupational stress scale. Results: Revealed that $51.8 \%$ of head nurses had high QWL and the highest percent of them had high quality of work life for the work context. Also, it was observed that $77.6 \%$ of head nurses had low stress level and $41.2 \%$ of them had high stress level for physician related stressors. Conclusion: The findings pointed to, that there was a negative a statistically significant correlation between quality of work life and occupational stress among head nurses. Recommendations: Therefore, the findings pointed for upgrading nurses' QWL through development of new strategies and systems to enhance work environment. And using advanced coping strategies to eliminate stress level among nurses.
\end{abstract}

Key Words: Head nurses , occupational stress, quality of work life 


\section{INTRODUCTION}

In the last years, a high quality of work life (QWL) is essential for organization to continue to attract and empower employees ,QWL is a comprehensive -wide program designed to improve employees satisfaction, empower employee, strengthening workplace learning and helping employees, better manage change and achieve a high level of personal satisfaction (Dargahi \&Yazdi, 2007) According to Greer and Plunkett (2007) QWL is define as " employees satisfaction with the diverse needs of resource, activities and outcomes that result from participation in the work environment .

Taylor and pinczuk (2010) identified the essential components of QWL as basic extrinsic job factors of wages, hours and work condition, and the intrinsic job notions of the nature of work itself. Taylor \&Pinczuk, (2010) suggested that number aspect could be added, including: individual power, social support, self- development, employee participation in management and use the principles of quality as fairness and equity.

In nursing, QWL focuses on the degree to which nurses are able to satisfy important personal needs through their experiences in the work, while achieving the organizational goal to make meaningful contributions to their organization (Brook and Anderson, 2001). It means keeping a good balance between work and personal life. In the light of this, the job should offer them an adequate salary, balance workload and located near their homes. Under these conditions would feel with satisfaction, have the opportunity for learning, self growth, and to be-fulfilled by their work (Has and Kerohan, 2006).

Quality of work life influences the performance and commitment of employees in various industries, including health care organizations (Huang et al., 2007). A high QWL is essential to attract new employees and retain a workforce. Consequently, health organizations are seeking ways to address issues of recruitment \& retention by achieving a high QWL (El-Malky, 2012). Many advantages can result from a high QWL for the employee, organization and consumer. These include strengthening organizational commitment, improving quality of care and increasing the productivity of both the individual and organization. According to Sirgy et al. (2011) a happy employee is more productivity, dedicated and committed. Both employers and employees now better appreciate the importance of the quality of work life in an organization. 
Stress refers to psych-physiology response of living organism to a perspective challenge, change or threat. Occupational stress (job stress) is a psychosocial disorder which is an impact of the interaction between the worker and his work environment on the worker themselves. If left unidentified it can cause serious physical and physiological illness to the individual, which affects both the individual and the organization (Mohan et al., 2008). Occupational stress at work place was common, especially in health care organization and may occur due to stress factors at the individual level, or at the organization level or at the interface of both (Kumar and Suresh, 2011).

Yoder-Wise (2011) reported that nursing as a profession always had many sources of stress as workload, rotating shifts, high "patient" acuity, missing valuable information about the patient, ethical conflicts, dealing with death and acute illness, role ambiguity, job insecurity, job dissatisfaction, poor communication or mistrust existed between nurses and physicians \& bad relationship with other health care workers, lack of resources, delayed or misunderstood orders, working in a noisy environment, improper structure of practice setting, and lack of proper nurses`educational preparation for the job.

\subsection{Significance of the study:}

High QWL increasing job satisfaction, decreasing rates of complaints and absenteeism among employees, and increasing work stress level (Sirgye et al., 2011). Moreover, Steliar (2010) stated that managing stress becomes vital in order to keep up job performance through changing the environment, making the environment less competitive between employees and enhance the relationship between employees and managers. Because occupational stress is a worrying and expensive phenomenon and nurses suffer from high stress levels among all occupations. So, this study aimed to investigate the relationship between quality of work life and occupational stress among head nurses at Port Said hospitals.

1.2 Research Aim: Investigate the relationship between quality of work life and occupational stress among head nurses in port said hospitals.

\subsection{Research Objectives:}

1. Determine the quality of work life level among head nurses.

2. Determine the occupational stress level among head nurses. 
3. Find out the relationship between the quality of work life andoccupational stress among head nurses.

\subsection{Research Question:}

(1) What is the quality of work life level among head nurses?

(2) What is occupational stress level among head nurses?

(3) Is there a relationship between the quality of work life and occupational stress among head nurses?

\section{SUBJECT AND METHODS:}

\section{Material}

1.1 Research design: A descriptive co-relational research design was utilized in this study.

2.1 Setting: The study was conducted in inpatients department at nine hospitals, seven of them affiliated to Ministry of health and another two hospitals affiliated to Health Insurance at Port Said City namely:

1. Port Said general hospital.

2. Elzehor hospital.

3. El-Naser hospital.

4. Alramed hospital.

5. Port foud general hospital.

6. Almasah Albahary hospital.

7. Alhomyat hospital.

8. Almobraa hospital.

9. Eltadamon hospital. 
3.1 Subjects: The subjects of this study included all head nurses who are working in the above mentioned settings with total numbers (85).

\section{Inclusion criteria:}

1- Agree to participate in the study.

2- They have at least one year of experience in their current job.

Exclusion criteria:

Head nurses with experience less than one year

4.1Tools of data collection: Data for this study was collected by using two tools. These include Quality of Nursing Work Life Scale (QNWL) and Occupational Stress Scale.

\section{First Tool:}

This tool consists of two parts:

First Part: This part included head nurses' personal \& job characteristics as age, educational level, social status, sex, number of children, and years of experiences.

\section{Second Part: Quality of Nursing Work Life Scale (QNWL):}

That was developed by Brooks (2001) to measure the QWL among nurses. It is selfcompletion questionnaires which contain 42 items in the following 4 subscales: work life / home life (7), work design (10), work context (20), and work world (5). Cronbach's alpha for Brooks' scale is 0.89

The work life/home life dimension is defined as the interface between the work and home life of the nurse. The work design dimension is the composition of nursing work and describes the actual work that nurses perform. The work context dimension includes the practice settings in which nurses' work and explores the impact of the work environment on both nurse and patient systems. Finally, the work world dimension is defined as the effects of broad societal influences and changes on the practice of nursing. 


\section{Scoring System:}

Subjects responses were measured on a six point Likert scale, with (1) indicating strongly disagree, (2) moderately disagree, (3) disagree, (4) agree, (5) moderately agree, and (6) strongly agree. For each domain, the scores of the items were summed-up and the total was divided by the number of the items, giving a mean score for each part. These scores were converted into a percentage score. The total possible score for the Brooks' scale can range from 42 to 252 . QWL was considered high if the percent score was $\geq 60 \%$ and low QWL if the percent score was $<60 \%$ (NIOSH, 2002).

\section{SECOND TOOL: (Occupational Stress Scale):}

This scale was developed by Holmes and Rahe (1987) and adopted from Mohamed (2010) to assess the occupational stress level among head nurses. The scale consists of 52 statements and divided into six subdivisions as the following;

1/ Role stressors, Task stressor, Patient stressor, Physician stressors, Human and physical resources stressor and Educational / vocational stressors

\section{Scoring system:}

The scoring system was based on nurses` responses that were high, moderate and low and scored as 2, 1 and 0 respectively. For each domain, the scores of the items were summed-up and the total was divided by the number of the items, giving a mean score for each part. These scores were converted into a percentage score. Occupational stress level was considered high if the percent score was $\geq 75 \%$, moderate stress level if the percent score was from $65 \%-75 \%$, and low stress level if the percent score was $<65 \%$ (Mohamed ,2010).

\section{Methods}

\section{Pilot Study:}

A pilot study was carried out on $10 \%$ of head nurses (8) who were selected randomly before starting data collection to test the applicability, feasibility and clarity of the tools and to test the sequence of questions and time needed to complete the tools. Therefore, the rewording or rephrasing of the statements was done. Those who took part in the pilot study were included in the study. Cronbach's Alpha reliability test was done for translated QOWL scale, whereas its value was 0.87 . 


\section{Ш- Administrative Design:}

Official letter from the Port Said Faculty dean directed to the hospital manager to take formal agreement to carry out the study, and then the aim of the study was explained to the head nurses included in the study after taking their permission to participate in the study. All head nurses assured about confidentiality of the information gathered and it is only for the purpose of the study.

\subsection{Ethical Considerations:}

*Ethical approval was obtained from the research ethics committee of the faculty of nursing in Port Said University.

*An official permission to conduct the study was obtained from hospital directors.

2.2 statistical Data Analysis: Data was coded, computerized and then analyzed using the Statistical Package for Social Science (SPSS) software package version 20.0.Using frequency $\&$ percentage for qualitative data, mean and standard deviation for quantitative data, $\chi^{2}$ Test, and Monte Carlo test were used. In addition Pearson correlation coefficient test was used. The statistical significance was considered at $\mathrm{P}$-value $\leq 0.05$ and highly significance at $\mathrm{P} \leq 0.001$.

\section{RESULTS:}

Table (1): As shows personal \& job characterstics of the studied head nurses table shows that more than one third of the study sample was in age group 30 to less than 40 years old. Concerning educational level more than three quarters of them had nursing school diploma. Regarding years of experience in their current position (as a head nurse) $41.2 \%$ of them had experience from 5 years to less than fifteen years. While two fifth of the study samplehad nursing experience (as a nurse) from 15 years to less than 25 years. And majority of them was married.

Table (2): Shows the quality of work life domains among the studied head nurses, As table showed that $51.8 \%$ of studied head nurses had high quality of work life in hospitals, while $48.2 \%$ of them had low quality of work life. Also $62.4 \%$ of them had high quality of work life regarding work context \& environment. On other hand the lowest percent of them $(16.5 \%)$ were satisfied about quality of work life regarding work life / home life.

Table (3):Reveals the level of occupational stress domains among studied head nurses, As table shows that totally the majority of head nurses (77.6\%) had low stress level. 
Meanwhile the minority of them had high stress level. Additionally the highest percent of head nurses had low stress level regarding all domains of occupational stress.

Table (4): Display a correlation between QWL and occupational stress among head nurses. As evident in this table, there was negative statistically significant relationship between head nurses QWL and occupational stress at ( $p<0.0001)$.

Table (1): Personal and job characteristics of the studied head nurses $(n=85)$

\begin{tabular}{|c|c|c|}
\hline \multirow[b]{2}{*}{ Personal characteristics } & \multicolumn{2}{|c|}{ Studied head nurses } \\
\hline & No. & $\%$ \\
\hline \multicolumn{3}{|l|}{ Age (years) } \\
\hline $20-$ & 16 & 18.8 \\
\hline $30-$ & 33 & 38.8 \\
\hline $40-$ & 21 & 24.7 \\
\hline $50-\leq 60$ & 15 & 17.6 \\
\hline Min-Max & \multicolumn{2}{|c|}{$24.0-59.0$} \\
\hline Mean \pm SD & \multicolumn{2}{|c|}{$38.7 \pm 10.1$} \\
\hline \multicolumn{3}{|l|}{ Educational level } \\
\hline Nursing diploma & 67 & 78.8 \\
\hline Technical nursing diploma & 6 & 7.1 \\
\hline Nursing Bachelor & 12 & 14.1 \\
\hline \multicolumn{3}{|l|}{ Marital status } \\
\hline Single & 10 & 11.8 \\
\hline Married & 70 & 82.4 \\
\hline Widow & 5 & 5.9 \\
\hline \multicolumn{3}{|l|}{ Duration of nursing experience (years) } \\
\hline Less than 5 & 4 & 4.7 \\
\hline $5-$ & 24 & 28.2 \\
\hline $15-$ & 34 & 40.0 \\
\hline $25-$ & 13 & 15.3 \\
\hline $35-<45$ & 10 & 11.8 \\
\hline Min-Max & \multicolumn{2}{|c|}{$2.0-41.0$} \\
\hline Mean \pm SD & \multicolumn{2}{|c|}{$19.7 \pm 10.2$} \\
\hline \multicolumn{3}{|l|}{$\begin{array}{l}\text { Duration of nursing experience incurrent position } \\
\text { (years) }\end{array}$} \\
\hline Less than 5 & 13 & 15.3 \\
\hline $5-$ & 35 & 41.2 \\
\hline $15-$ & 22 & 25.9 \\
\hline $25-$ & 10 & 11.8 \\
\hline $35-<45$ & 5 & 5.9 \\
\hline Min-Max & \multicolumn{2}{|c|}{$1.0-40.0$} \\
\hline Mean \pm SD & \multicolumn{2}{|c|}{$14.9 \pm 10.4$} \\
\hline
\end{tabular}


Table (2): Quality of Nursing Work Life domains among the studied head nurses ( $\mathrm{n}=85$ )

\begin{tabular}{|l|c|c|c|c|}
\hline \multirow{2}{*}{$\begin{array}{c}\text { Quality of Nursing Work Life } \\
\text { domain }\end{array}$} & \multicolumn{2}{c|}{$\begin{array}{c}\text { Low } \\
(<\mathbf{6 0 \%})\end{array}$} & \multicolumn{2}{c|}{$\begin{array}{c}\text { High } \\
(\mathbf{6 0 \%}>)\end{array}$} \\
\cline { 2 - 5 } & No. & \% & No. & \% \\
\hline Work life/home life & 71 & 83.5 & 14 & 16.5 \\
\hline Work design & 38 & 44.7 & 47 & 55.3 \\
\hline Work context and environment & 32 & 37.6 & 53 & 62.4 \\
\hline Nursing profession & 50 & 58.8 & 53 & 62.4 \\
\hline Total score & 41 & 48.2 & 44 & 51.8 \\
\hline
\end{tabular}

Table (3): level of occupational stress domains among studied head nurses $(n=85)$

\begin{tabular}{|l|c|c|c|c|}
\hline \multirow{2}{*}{ Occupational Stress Scale } & \multicolumn{2}{c|}{ Low $(<65 \%)$} & \multicolumn{2}{c|}{ High $(\mathbf{7 5 \%}\rangle)$} \\
\cline { 2 - 5 } & No. & $\%$ & No. & $\%$ \\
\hline Job related stressors & 59 & 69.4 & $\mathbf{2 6}$ & $\mathbf{3 0 . 6}$ \\
\hline Task related stressors & $\mathbf{7 2}$ & $\mathbf{8 4 . 7}$ & 13 & $\mathbf{1 5 . 3}$ \\
\hline Patient related stressors & 59 & 69.4 & $\mathbf{2 6}$ & $\mathbf{3 0 . 6}$ \\
\hline Physician related stressors & 50 & 58.8 & 35 & 41.2 \\
\hline $\begin{array}{l}\text { Human and non-human resources related } \\
\text { stressors }\end{array}$ & 60 & 70.6 & 25 & 29.4 \\
\hline Education and profession related stressors & 69 & $\mathbf{8 1 . 2}$ & 16 & $\mathbf{1 8 . 8}$ \\
\hline Total score & 66 & 77.6 & 19 & 22.4 \\
\hline
\end{tabular}

Table (4): correlation between QWL and occupational stress among head nurses $(n=85)$

\begin{tabular}{|c|cc|}
\hline \multirow{2}{*}{ Items } & \multicolumn{2}{|c|}{ Occupational stress } \\
\cline { 2 - 3 } & $\mathbf{r}$ & P \\
\hline & & -0.0001 \\
\hline QWL & -0.505 & \\
\hline
\end{tabular}

\section{DISSCUSION:}

The results of the present study revealed that slightly more than one third of the study sample was in age group 30 to less than 40 years old. Concerning educational level more than three quarters of the study sample had nursing school diploma. Regarding years of experience in their current position (as a head nurse) $41.2 \%$ of them had experience from 5 years to less than fifteen years. While two fifth of the study sample had nursing experience (as a nurse) from 15 years to less than 25 years. And majority of them was married. 


\section{Quality of work life:}

Findings of the present study proved that totally more than half of head nurses had high level of quality of work life, while the rest had low level of quality of work life. This finding was supported by Reena(2009)who found that the majority of participants had a high level of QWL. This finding was contracted with that of Bolhari et al., (2012) who studied the impact of occupational stress on quality of work life among the staff of eworkspace and indicated that the mean QWL level is located in the medium QWL range and only 7.74\% suffer from low QWL level. QWL is a philosophy or set of principals which holds that people are trustworthy, responsible and capable of making valuable contribution to the organization (Rose et al.; 2006). Also, Quality of work life includes concepts such as job security, reward systems, training and career advancements opportunities and participation in decision making (Saraji \& Dargahi, 2006).

Accordingly, one of the major issues in the field of attracting more seekers to the nursing profession is changing the image of the nursing profession. A negative image has negative consequences, in the quality and quantity of persons who choose nursing while a positive image leads to several positive professional outcomes (Ibrahim, Akel and Mohammed ,2015).

Additionally, head nurses should be aware of the fact that when consulting clients or caring for someone, patients are observing nurses and form impressions (a mental picture-image) about the appearance, posture, interaction, communication, competence, character, and commitment of the nurse. Whether good or bad, these impressions usually very fast spread around the health facility and community (Tenhoeve, Jansen, \& Roodbol, 2014). In conclusion, Evans (2002), in a Yorkshire, UK study exploring the district nurses' perception of occupational stress and satisfaction found that job image was among the six major stress factors for the nurses.

Regarding the relation between quality of work life levels and personal and job characteristics of the studied head nurses. The present study revealed that there was no relation between levels of quality of work life among studied head nurses and there personal and job characteristics in terms of age, educational level, marital status, and years of experience. These findings agreed with (Boonrod., 2009 \& Dargahi et al.,2012) who reported that there was no significant relationship between age and QWL. Also in the same line with Moradi et al.,(2014) showed that there was no significant correlation between age and QWL. These findings are inconsistent with Nayeri et al., (2011) who 
found that there is a close correlation between age and QWL. Menwhile, Khaghani et al., (2008) reported that there is an inverse correlation between age and QWL.

\section{Occupational stress}

Findings of the present study proved that totally the majority of head nurses $77.6 \%$ had low stress level, meanwhile, the minority of them had high stress level. In this respect, Smith (2000) who study the scale of perceived occupational stress in $U K$ and found that approximately $20 \%$ of the sample reported that they had very high or extremely high levels of stress at work. In contrast, Lovy and Sunil(2010) asserted that occupational stress is a worrying and expensive phenomenon in nursing. And some occupations as nursing profession are more stressful than other caring professionals, and nurses frequently suffer from high stress levels.

Additionally, Kumar \& Suresh (2011) mentioned that most of the subjects had increased score of perceived Job stress. In contradiction to the current study findings, a study done in United Arab Emirates showed that $0.5 \%$ of participants had a high stress level, $44.4 \%$ had a low stress level, and 55.1\% had a moderate stress level (Mozhdeh et al., 2008). Meanwhile, Bolhari et al., (2012) found that the majority of participant had medium occupational stress; there are only $2.9 \%$ with high occupational stress level and $7.7 \%$ with low occupational stress level.

Regarding correlation between occupational stress and quality of work life among the studied head nurses, the findings indicated that there was a negative a statistically significant correlation between dimensions of quality of work life and occupational stress. This result was on the same line with Elder, (2004); Khowaja, et al., (2005) and Lambert(2008) who reported that nursing shortage and excessive workload in units were important factors of job stress. Nyathi \& Jooste, (2008) added that resulted in absenteeism in the work place. Moreover, a study done at state of health in Brazilian nurses, Stacciarini et al., (2004) reported that lack of recognition, lack of status of the nursing profession, lack of autonomy, low salaries, were sources of stress and dissatisfaction for nurses. In this context, Dowden and Tellier, (2004) reported that the most effective factors on job stress found that attitude toward job (participation in making decisions, satisfaction, job commitment) and some special aspects (dangers and hardships of a job), are the most powerful factors that affect job stress. 
Furthermore Najimi et al., (2012) stated that one of the most effective factors which decrease job stress is participation in making decisions which make some mutual relations between bosses and employees. In general, structures which gave option to employees make less stress and will improve the sense of autonomy, confidence, and responsibility. Support of supervisor, relations, and collaboration in decision making are characteristics of an enabling atmosphere which make the nurse independent and able to provide services in a stressful environment.

\section{CONCLUSION:}

In the light of the present study findings, it can be concluded that more than half $(51.8 \%)$ of head nurses had high level of quality of work life, while the rest had low level. The majority of head nurses (77.6\%) had low stress level; meanwhile, the minority of them had high stress level. Additionally, there was no relation between levels of quality of work life among studied head nurses and occupational stress and their personal and job characteristics in terms of age, educational level, marital status, and years of experience. Finally, there was a negative statistically significant correlation between quality of work life and occupational stress among head nurses.

\section{RECOMMENDATION:}

According to the findings of the study, the following recommendations are proposed:

Nurse Managers should create a friendly work environment, as it had a major impact on the head nurses' QWL.

Implementing QWL program can improve head nurses QWL as it is associated with improving job satisfaction, organizational commitment, organizational effectiveness, productivity, quality of life and reducing turnover intention.

\section{REFERENCES:-}

Bolhari, A., Rezaeean, A., Bolhari, J., \& Zare, F. (2012). The impact of occupational stress on quality of work life among the staff of e-workspace. World Academy of Science, Engineering and Technology, 67(2012), 314-318

Brookes, B.A. and Anderson, M.A.(2001): Defining quality of nursing work life. Journal of Nursing Economics, 23(6). 319-26. 
Daragahi, H., and Nasle Saraji,J. (2007): An approach model for employees improving quality of work life (IQWL) Iranian journal of public health. 36, 81-86

Dowden, C., \& Tellier, C. (2004). Predicting work-related stress in correctional officers: A meta-analysis. Journal of Criminal Justice, 32, 31-47.

Elder, K. R., \& Grant, M. (2004). Modeling elastic and plastic deformations in nonequilibrium processing using phase field crystals. Physical Review E, 70(5), 051605.

Has, $Y$ and Keronhan, $(G) .(2006)$ : Dimensions of hospitals nurses quality of working life. Journal of advanced nursing .54(1). 120-131.

Khwaja, H. A., \& Narang, A. (2008). Carbonyls and non-methane hydrocarbons at a rural mountain site in northeastern United States. Chemosphere, 71(11), 2030-2043.

Kumar, P. S., Nizar, S. S., Sundaramurthy, J., Ragupathy, P., Thavasi, V., Mhaisalkar, S. G., \& Ramakrishna, S. (2011). Tunable hierarchical TiO 2 nanostructures by controlled annealing of electrospun fibers: formation mechanism, morphology, crystallographic phase and photoelectrochemical performance analysis. Journal of Materials Chemistry, 21(26), 9784-9790.

Kumar,T. A., andSuresh,D.R.,(2011): Clinical Significance of Perceived Occupational Stress Influencing Body Mass and Osteopenia: A Pilot Study. Global Journal of Medical research, 11 (4): 42-47.

Lambert, G., Schlaich ,M.; Lambert, E.; Dawood, T.; Esler, M., (2010). Stress reactivity with increased cardiovascular risk: A role for the sympathetic nervous system. Hypertension, 55 (6) : e20

Lovy. s and Sunil. k(2010) :An International Study of Work Stress with Types of Workers , 17(1):

Mazoochi, T., Salehnia, M., Valojerdi, M. R., \& Mowla, S. J. (2008). Morphologic, ultrastructural, and biochemical identification of apoptosis in vitrifiedwarmed mouse ovarian tissue. Fertility and sterility, 90(4), 1480-1486.

Mohamed, N. E. (2010): The relationship Between Occupational Stress And Organizational Commitment Among Nurses In Hospitals In Port-Said City, Unpublished Thesis. Suez Canal Un., Fac.Ng., M.Sc. 
Mohan, P., Padmanabhan, V. N., \& Ramjee, R. (2008, November). Nericell: rich monitoring of road and traffic conditions using mobile smartphones. In Proceedings of the 6th ACM conference on Embedded network sensor systems (pp. 323-336). ACM.

Najimi, A., Goudarzi, A. M., \& Sharifirad, G. (2012). Causes of job stress in nurses: A cross-sectional study. Iranian journal of nursing and midwifery research, 17(4), 301.

Nyathi, M., \& Jooste, K. (2008). Working conditions that contribute to absenteeism among nurses in a provincial hospital in the Limpopo Province. Curationis, 31(1), 28-37.

Saraji, G. N., \& Dargahi, H. (2006). Study of quality of work life (QWL). Iranian journal of public health, 35(4), 8-14.

Saraji, G.N., and Daraghi, H.(2006): study of quality of work life. Iranian Journal of public Health, 35(4),8-14.

Sirgy, M. J., Kruger, P. S., Lee, D. J., \& Yu, G. B. (2011). How does a travel trip affect tourists' life satisfaction?. Journal of Travel research, 50(3), 261-275.

Sirgy, M.J., Efraty, D., Siegel, P. and Lee, D.J.(2001): A new measure of quality of work life (QWL) based on need satisfaction and spillover theories, Social Indicators Researches, 55(3). 421-10.

smith, D. R., Padilla, W. J., Vier, D. C., Nemat-Nasser, S. C., \& Schultz, S. (2000). Composite medium with simultaneously negative permeability and permittivity. Physical review letters, 84(18), 4184.

Smith. A.(2000): The scale of perceived occupational stress, Occup. Med. 50( 5): pp. 294-298.

Stacciarini, J. M. R., \& Troccoli, B. T. (2004). Occupational stress and constructive thinking: health and job satisfaction. Journal of advanced nursing, 46(5), 480-487.

Yoder-Wise, P. S. (2011). The doctor of nursing practice: A national workforce perspective. Nursing outlook, 59(5), 258. 